\title{
Effects of parental intervention on behavioural and psychological outcomes for Kurdish parents and their children
}

Hoshiar Sangawi ${ }^{1}$, John Adams ${ }^{1}$ and Nadja Reissland

Department of Psychology, University of Durham, Durham, United Kingdom (Correspondence to: H. Sangawi: hoshiar1980@yahoo.com; hoshiar. muhammad@durham.ac.uk).

\begin{abstract}
Background: Parenting interventions are rarely offered in developing countries and there is an urgent need to include low-income countries.

Aims: To examine the effectiveness of Systematic Training for Effective Parenting (STEP) among Kurdish parents and their children.

Methods: This was a randomized control pilot trial using pre- and post-test scores of 17 mothers (mean age 35.25 years, standard deviation 4.3 years; range: $29.58-45.3$ years) who agreed to participate in the intervention. We utilized the Alabama Parenting Questionnaire (APQ) to assess parenting style; Parental Stress Scale (PSS) to investigate parental stress; and Step Parenting Assessment Technique (SPAT) to identify whether participants in the treatment group had learned the material of the intervention.

Results: There were significant differences between the groups on 3 subscales of the APQ: mother involvement subscale, $F(1.13)=25.81, P<0.001, \eta^{2}=0.67$; inconsistent discipline subscale, $F(1.13)=25.46, P<0.001, \eta_{p}{ }_{p}=0.66$; and corporal punishment subscale $F(1.13)=17.3, P<0.005, \eta_{p}^{2}=0.57$. A significant difference between groups was also found on the PSS, $F(1.13)=19.63, P<0.001, \eta_{\mathrm{p}}^{2}=0.60$. The changes were sustained over a 3-month period. No significant differences were found in academic self-concept and behavioural problems between children whose mothers attended STEP and others whose mothers did not attend.
\end{abstract}

Conclusions: The STEP programme appears to promote parenting style and reduce the level of parental stress in Kurdish mothers.

\section{Trial Registration: IRCT2016032527125N1}

Keywords: Academic self concept, behavioural problems, intervention, parenting styles, parental stress.

Citation: Sangawi H; Adams J; Reissland N. Effects of parental intervention on behavioural and psychological outcomes for Kurdish parents and their children. East Mediterr Health J. 2018;24(5):459-468. https://doi.org/10.26719/2018.24.5.459

Received: 13/01/16; accepted: 20/07/17

Copyright (c) World Health Organization (WHO) 2018. Some rights reserved. This work is available under the CC BY-NC-SA 3.0 IGO license (https:// creativecommons.org/licenses/by-nc-sa/3.o/igo).

\section{Introduction}

There is widespread evidence that positive parenting styles play a significant role in decreasing behavioural problems among children $(1,2)$. Parenting training is considered to be an effective approach to improve relationships between children and their parents (3). Bunting (4) examined the findings from several systematic reviews that summarized the effect of a variety of parenting programmes. Their results indicated that parenting programmes have a positive influence on improving behavioural and psychological outcomes for parents and children including child behaviour, parent-child interaction and knowledge, and maternal self-esteem and stress. Furthermore, the results of a meta-analysis by Barlow et al. (5), found that parenting programmes can be effective in alleviating maternal depression, reducing stress, increasing self-esteem and improving the mother's relationship with her spouse.

The Systematic Training for Effective Parenting (STEP) is considered to be helpful in improving parentchild interaction and promoting parental experiences by educating parents about effective parenting methods and thereby improving child behaviour (6). Based on a review and critique of 16 major parental education programmes, STEP is considered to be one of the best programmes, using 3 review criteria: programme readiness, strength of scientific base, and empirical evidence of programme effectiveness (7).

There has been considerable empirical research evaluating the effectiveness of the STEP programme on improving parenting styles and psychological adjustments. For instance, in a quasiexperimental study by Jonyniene et al. (8), the efficacy of the STEP programme was examined amongst Lithuanian parents. The findings showed noteworthy improvements in the parenting styles and parental negative perceptions of their child's behaviour. Additionally, in a study by Larson (9), 56 family dyads of parents and their target children (aged 12-15 years) participated in STEP intervention. There was a significant increase in authoritative (positive) parenting and a significant decrease in authoritarian (negative) parenting style. Pan and $\mathrm{Wu}(10)$ also carried out an intervention study of STEP with 11 Chinese parents that showed improvement in parent-child relationships. 
Huebner (11) demonstrated the benefit of STEP among 199 parents and found an improvement in quality of the family environment alongside a significant decrease in parenting stress, particularly that originating from parent-child interactions.

These studies provide evidence for the impact on parents; however, STEP has also been found to substantially improve children's behaviour. More specifically, in the study by Larson (9) parents reported that their teenage children's externalizing behaviour was significantly reduced after participating in a STEP intervention. Wantz and Recor (12) also carried out a study with 11 families who participated in a 6-week STEP intervention. The results showed a noteworthy improvement in the children's behaviour as a result of their parent's participation in the programme. Overall, these results indicate that the STEP programme plays an important role in the psychological and developmental wellbeing of both parents and their children.

Parenting interventions have been widely carried out in Europe and America. For instance, a systematic review by Thomas et al. (13) indicated that from 14 included studies, $75 \%$ were conducted in the United States of America, $17 \%$ in Canada and $8 \%$ in the United Kingdom of Great Britain and Northern Ireland. The lack of research in developing countries is a clear gap in the literature. It has been argued that most parenting training programmes have been tested in high-income countries and that there is an urgent need to include low-income countries $(14,15)$. Currently, there is no substantial body of evidence to show that STEP has an effect on parents and their children in Middle Eastern countries, including low-income areas such the Kurdistan Region of Iraq. The importance of such studies was highlighted in a crosssectional study of 275 Kurdish college students, reporting that during childhood $20 \%$ of students had encountered at least 1 negative treatment, including physical and emotional abuse (16). It has also been reported by mass media and the police that, in 2014, Kurdish children aged 3-12 years were the victims of violent treatment by their parents, and in 1 instance, this lead to the death of a 5-year-old child (http://archive.xendan.org/dreja. aspx? $=$ hewal\&jmara $=7273 \&$ Jor $=1$ ).

\begin{tabular}{lccc}
\hline \multicolumn{3}{|c}{ Table 1 Demographic characteristics of mothers } \\
\hline Variables & $\%$ & $\begin{array}{c}\text { Treatment } \\
\text { group }\end{array}$ & $\begin{array}{c}\text { Control } \\
\text { group }\end{array}$ \\
\hline $\begin{array}{l}\text { Educational background } \\
\text { Low }\end{array}$ & $71 \%$ & 7 & 5 \\
$\quad$ High & $29 \%$ & 2 & 3 \\
Mean age & & $36.1 \mathrm{yr}$ & $34.5 \mathrm{yr}$ \\
& & $\mathrm{SD}(5.01)$ & $\mathrm{SD}(3.6)$ \\
Employment status & & & \\
$\quad$ Employed & $35 \%$ & 3 & 3 \\
$\quad$ Unemployed & $65 \%$ & 6 & 5 \\
Marital status & & & \\
$\quad$ Married & $94 \%$ & 8 & 8 \\
$\quad$ Divorced & $6 \%$ & 1 & 0 \\
\hline
\end{tabular}

$S D=$ standard deviation .
These findings indicate that parents in this region need significant support to improve their parenting skills. Currently, however, there is no empirical research on the efficacy of educational and counselling interventions with parents in Kurdish society. The current study examined whether participation in the STEP as a standardized, highly structured parental education intervention improved Kurdish parenting styles and decreased the level of parental stress. Based on previous research it was hypothesized that mothers participating in STEP would significantly improve their parenting styles and decrease their level of stress compared to those who did not attend STEP.

\section{Methods}

\section{Participants}

Seventeen mothers (mean age 35.25 years, standard deviation 4.3 years; age range: $29.58-45.3$ years) agreed to participate in the intervention. Mothers were randomly assigned (following a simple randomization procedure) to the treatment $(n=9)$ or control $(n=8)$ group. One mother in the treatment group could only attend 4 sessions and her post-test data could not be collected at the end of the programme. A questionnaire filled out by mothers provided information about their demographic background (Table 1).

\section{Procedure}

The sample derived from a group of mothers whose children (in 6th grade) had taken part in a previous study (17). Based on the Strengths and Difficulties Questionnaire (SDQ) (18) symptom scores, teachers reported that 37 of 199 children had a high score in $\geq 1$ of the behavioural problems subscales (19). Of these, 32 children were also found to have higher than cut-off scores for negative parental style. Consequently, the mothers of these 32 children were asked to participate in the STEP programme.

Mothers rather than fathers were asked to participate because Kurdish children spend more time at home with their mothers than their fathers as the latter are primarily responsible for the financial needs of the family. Maternal rather than paternal involvement in parenting is a significant predictor of levels of Kurdish children's academic self-concept and behavioural problems (17). Although there is no doubt that fathers have a significant role in their children's development (20), it has been established that mothers have a greater impact on children's psychological outcomes (21). Another criterion was that mothers had to have $\geq 1$ child in 6th grade (age 11-12 years). Mothers had to be Kurdish speakers and they also had to be no older than 50 years.

An invitation letter was sent to the 32 mothers via their children's schools outlining the purpose of the study and a brief description of the STEP programme. In the parent's consent form it was stated that their responses were confidential and would only be shared with the research team. Mothers were also informed that they would be free to withdraw at any time without giving a 
reason. Seventeen mothers agreed to participate in the programme.

The treatment (STEP) group was led by the researcher and his assistant in weekly workshops lasting 2 hours. Approximately 1 week before the initial treatment, baseline measures were collected through questionnaires from the treatment and control groups. Participants in the treatment group were asked to return the questionnaires before starting the training sessions. After the treatment procedure, lasting 7 weeks, post-test measures were requested from both groups.

Three months after the intervention, the questionnaires were sent to the mothers in both groups via their child's school to follow up any changes in parenting styles and parental stress during the intervening period. We also examined whether any positive changes in children's academic self-concept and behavioural problems were observed after their mothers attended the STEP. The data obtained for the children previously (21) were used as the pretest baseline. To obtain post-test data, the children ( 12 boys and 4 girls) were asked to fill in the Myself-as-a-Learner Scale (MALS) (22) to measure their academic self-concept. Teachers also completed the SDQ (18) to identify children's behavioural problems for a second time (post-test).

\section{Measures}

\section{APQ: version 2: parental form}

The APQ version 2 parental form (23) was used to measure parenting styles. The parental form of APQ consists of 42 items that require parents to respond on a 5-point Likert scale ranging from 1 (Never) to 5 (Always). The APQ covers 5 dimensions or subscales: parental involvement (10 items; e.g., "You have a friendly talk with your child") and positive parenting (6 items; e.g., "You let your child know when he/she is doing a good job with something"). These 2 dimensions can be considered as a positive composite. The following dimensions are considered as a negative composite, including poor parental monitoring, inconsistent discipline and corporal punishment. Poor parental monitoring comprises 10 items, such as "You don't tell your child where you are going"; inconsistent discipline includes 6 items, such as, "You threaten to punish your child and then do not actually punish him/ her"; and corporal punishment comprises 3 items, such as "You slap your child when he/she has done something wrong". The 7 remaining items have not been assigned to a specific style, but they also assess discipline practices other than corporal punishment. These items have been included in the APQ to avoid an implicit negative bias for the corporal punishment items (23). The measure of each APQ subscale was obtained by summing the scores of its items. In terms of the reliability, apart from corporal punishment, adequate coefficients $(>0.70)$ were reported for the APQ subscales.

\section{PSS}

The PSS (24) was used to measure the level of parental stress. The PSS is a self-reporting scale that consists of 18 positive and negative items rated on a 5-point Likert scale ranging from 1 (strongly disagree) to 5 (strongly agree). The positive items 1, 2, 5-8, 17 and 18 should be reverse scored giving 5 (strongly disagree) to 1 (strongly agree). Parents are asked to agree or disagree with items in terms of their typical relationship with their children. An example of a positive item would be "I am happy in my role as a parent" and "The behaviour of my child(ren) is often embarrassing or stressful to me" is a negative item. The total score is obtained by summing up the values for each item. A higher score indicates a higher level of parental stress, and overall possible scores on the scale range from 18 to 90 . The scale can be used for the evaluation of parental stress for both parents of children with and without clinical problems (24). The reliability of the PSS has been described as adequate, as an $\alpha$ coefficient of 0.83 and test-retest reliability of 0.81 were found in the study of Berry \& Jones (24). In the current study, an $\alpha$ coefficient of 0.79 was obtained.

\section{SPAT}

SPAT (6) is a questionnaire that was designed for use during the STEP programme to ensure that the participants in the treatment group learn the material from the STEP programme. SPAT comprises 20 questions and participants are asked to agree or disagree with items in terms of their typical relationship with their children. Each item can be rated on a 4-point scale: 1 (strongly disagree) to 4 (strongly agree). Higher scores on the scale at the end of the programme demonstrate that participants have greater knowledge and understanding of the STEP programme concepts. The $\alpha$ coefficient was 0.72 in the present study.

All questionnaires used in this study were translated and back-translated to Kurdish by 3 professionals; 2 of whom were fluent in both English and Kurdish and an English native speaker who evaluated the content equivalence of each item.

\section{Study design}

We used a randomized controlled design using preand post-test scores in this pilot trial. The intervention tested was a 7-week structured parent educational group programme. Mothers assigned to the control group did not receive any intervention, but completed the questionnaires at the same time as the treatment groups. This was a proof of principle study of whether STEP was effective for Kurdish mothers.

\section{Study setting}

The programme was held at Kankawa Primary School in Sulaymaniyah City. Some parents used transportation (via buses or taxis) when attending the sessions. Thus, for each session 7500 Iraqi dinar (US\$ 6.5) was given to the parents as reimbursement.

\section{Intervention (treatment)}

The age-appropriate STEP programme can be typically taught through 7-9 weeks and is presented in a group workshop format with an optimal class size consisting of 6-14 parents. In terms of the lessons, each workshop takes $\sim 2$ hours. The workshops include information about 
parental behaviour and style, exploring alternative ways for parental behaviour and expressing different ideas and feelings, understanding the reasons for children's misbehaviour, and developing children's responsibilities and confidence. The programme also includes videos that demonstrate examples of effective and ineffective family interactions.

In the current study 7 sessions of $\sim 2$ hours were taught. The leader reviewed the purpose of STEP and outlined the topics that centred around the following 7 topics based on the STEP parent handbook: (A) understanding yourself, your child and the reason behind the child's misbehaviour; (B) understanding children's misbehaviour and choosing an effective response for this behaviour; (C) encouraging your child to promote positive behaviour; (D) communication: how to listen to your child's feelings and talk to your child; (E) helping children cooperate; (F) discipline that makes sense; and (G) choosing your approach (6).

\section{Data analysis}

SPSS version 21 was used for all data analyses. Frequencies were calculated for the demographic characteristics of the study population. Descriptive statistics (means and standard deviations) were also used. Independent sample $t$ test analyses were performed to examine differences between groups before starting the intervention. Hypotheses were tested by analysis of covariance (ANCOVA) to investigate whether the adjusted group means differed significantly from each other. ANCOVA has been shown to have benefits over repeated measures, such as a higher power (larger F ratios) and smaller standard errors (25). Therefore, the assumptions of ANCOVA were checked to make sure that the data were suitable.

Skewness and kurtosis values for each variable were assessed based on Kline's recommendation (26) proposing that the skewness value for a variable should be $<3$ and kurtosis should be $<8$. No skewness or kurtosis values for any variables in the current study were above those recommended cut-offs and no significant deviations from normality were detected. With regard to the effect size, Cohen's $d$ value (as assessed by Becker's effect-size calculator) and partial eta-squared $\left(\eta_{\mathrm{p}}^{2}\right)$ were used to determine the effect size. According to Cohen's $d$ (1992) guidelines, 0.2 is a small effect, 0.5 is a moderate effect and $\geq 0.8$ is a large effect. Suggested norms for $\eta^{2}$ have been shown to be: small $=0.01$; medium $=0.06$ and large $=0.14(27)$.

\section{Results}

\section{Analysis 1: before the training session}

Prior to the STEP programme, an independent samples $t$ test was performed to test for differences between the treatment and control groups for the pretest scores of the APQ and PPS. There were no significant differences in pretest scores between the groups in each of the APQ subscales: mother involvement, $t(15)=0.20, d=0.11$; positive parenting, $t(15)=0.66, d=0.32$; inconsistent discipline, $t(15)=\_0.14, d=\_0.07$; poor parental monitoring, $t(15)=0.43, d=0.20$; corporal punishment, $t(15)=0.22, d=$ 0.08. No significant difference was found in PSS scores, $t$ $(15)=\_0.84, d=\_0.41$ ) between the treatment and control groups.

\section{Analysis 2: after training session}

After completion of the intervention, the data from 16 mothers were entered into the analyses. To test the hypothesis that mothers participating in STEP would significantly improve their parenting style and have significantly lowered stress levels compared to the controls, ANCOVA (with pretest scores as the covariate) was performed. ANCOVA showed significant differences between groups for 3 subscales of the APQ: mother involvement, $F(1,13)=25.81, P<0.001, \eta_{p}^{2}=0.67$; inconsistent discipline, $F(1,13)=25.46, P<0.001, \eta_{p}^{2}=$ 0.66; and corporal punishment, $F(1,13)=17.3, \mathrm{P}<0.005$, $\eta_{p}^{2}=0.57$. A significant difference between groups was also found for the PSS, $F(1,13)=19.63, P<0.001, \eta_{p}^{2}=0.60$. No significant results were found for positive parenting $F(1,13)=0.77$ (not significant), and poor parental styles $F(1,13)=1.51$ (not significant).

To examine the differences in more detail, pairwise comparisons of the estimated marginal means with Bonferroni adjusted levels showed a significant mean difference between the groups. This suggested that the mothers in the treatment group achieved more positive improvements in parenting style (mother involvement, inconsistent discipline and corporal punishment) and a noteworthy decrease in parental stress as a result of their participation in the STEP programme.

To test whether the mothers in the treatment group learned the material from the STEP programme, a paired $t$ test compared the pretest and post-test scores of the SPAT questionnaire. The sample distributions were adequate and a high association between the 2 conditions $(r=0.81, P<0.05)$ was found, suggesting that the paired $t$ test was suitable in this case. Consequently, the result showed that the mothers' post-test mean score in SPAT was significantly higher than the pretest mean, $t(7)=$ $-3.28, \mathrm{P}<0.05, d=-0.70$.

Although the findings overall indicate that there were some improvements in the parenting style and parental stress for the treatment group, it was unclear whether the changes would be sustained over time. In addition, it was not clear whether the STEP mothers improved parenting would affect their children's academic self-concept and behavioural problems. Therefore, we followed up the mothers and their respective children after 3 months.

Analysis 3: differences in parenting styles and parental stress (pretest to follow-up)

In this analysis we aimed to address the following questions. First, did the improvements after attending STEP in parenting style and parental stress persist over a period of time? Second, were there any positive changes in children's academic self-concept and behavioural 
problems observed after their mothers attended the STEP?

Descriptive statistics from pretest to follow-up are shown in Table 2. To find group differences from pretest to follow-up, ANCOVA showed significant differences between the groups for 3 subscales of the APQ (mother involvement, $F(1,13)=13.2, P<0.005, \eta_{\mathrm{p}}^{2}=0.50$; inconsistent discipline, $F(1,13)=16.3, P<0.001, \eta_{\mathrm{p}}^{2}=0.56$; and corporal punishment, $F(1,13)=24.1, P<0.0005, \eta_{p}^{2}=0.65$. No other significant differences were found for the remaining APQ scales. Significant differences between groups were also found for the PSS, $F(1,13)=5.1, P<0.05, \eta_{\mathrm{p}}^{2}=0.28$.

Pairwise comparisons of the estimated marginal means with Bonferroni adjusted levels showed that mothers in the treatment group had a significantly higher mean score for mother involvement $(P<0.005)$ and lower scores for inconsistent discipline $(P<0.001)$, corporal punishment $(P<0.0005)$ and PSS $(P<0.05)$ than the control group had. It should be noted that the significant group differences from pretest to followup for mother involvement, inconsistent discipline and PSS were maintained, and that a larger drop for corporal punishment was noticed in the treatment group (Figure 1).

\section{Group differences in academic self-concept and behavioural problems of children}

The descriptive statistics for the children's data from baseline to post-test are shown in Table 3. ANCOVA (with baseline scores as the covariate) was performed to observe group differences in children's academic self-concept and behavioural problems for children whose mothers attended the intervention compared to children whose mothers were in the control group. The assumptions of ANCOVA were tested. ANCOVA showed no significant differences in academic self-concept and behavioural problems between children whose mothers attended STEP and others whose mothers did not attend (Table 4).

\section{Discussion}

The main aim of this study was to examine whether STEP is an effective intervention to improve parenting style and decrease parental stress among Kurdish mothers. A secondary objective was follow-up 3 months after intervention to measure academic self-concept and behavioural problems for those children whose mothers attended the programme. In common with previous findings $(9,11,28)$ our results showed significant improvements in parenting style and parental stress in the treatment group. Specifically, there were significant differences between the groups for 3 of the subscales of the $\mathrm{APQ}$ (i.e., mother involvement, inconsistent discipline and corporal punishment) and the PSS. Mothers in the treatment group scored higher on the mother involvement subscale and lower scores for inconsistent discipline, corporal punishment and PSS. Mothers reported through the SPAT questionnaire that they had a better understanding of the STEP programme materials after intervention.

The other two APQ subscales (positive parenting and poor parental monitoring) also showed improvements, although the difference was not found to be significant. There was no clear explanation for this; however, a possible reason for this result is that mothers might be more motivated to deal with inconsistent discipline and corporal punishment because STEP centres around topics related to this, for example, discipline that makes sense, understanding children's misbehaviour and choosing an effective response for this behaviour.

At 3 months after intervention, questionnaires were completed by both groups. The positive changes achieved from pre- to post-test were sustained at 3 months by the treatment group. Furthermore, there was a significant and sustained continuing decrease in the use of corporal punishment in this group. These findings are consistent with previous studies $(8,29,30)$ in which improvements in parenting style and parental stress as a result of parenting

\begin{tabular}{|c|c|c|c|c|c|c|c|c|c|c|c|c|c|c|c|}
\hline \multirow{3}{*}{ Variables } & \multicolumn{5}{|c|}{ Pretest scores } & \multicolumn{5}{|c|}{ Post-test scores } & \multicolumn{5}{|c|}{ Follow-up scores } \\
\hline & \multicolumn{2}{|c|}{$\begin{array}{c}\text { Treatment } \\
\text { group } \\
(n=9)\end{array}$} & \multicolumn{3}{|c|}{$\begin{array}{l}\text { Control group } \\
\qquad(n=8)\end{array}$} & \multicolumn{2}{|c|}{$\begin{array}{c}\text { Treatment } \\
\text { group } \\
(n=8)\end{array}$} & \multicolumn{3}{|c|}{$\begin{array}{l}\text { Control group } \\
\qquad(n=8)\end{array}$} & \multicolumn{2}{|c|}{$\begin{array}{c}\text { Treatment } \\
\text { group } \\
(\mathbf{n}=\mathbf{8})\end{array}$} & \multicolumn{3}{|c|}{$\begin{array}{l}\text { Control group } \\
\qquad(n=8)\end{array}$} \\
\hline & $\mathbf{M}$ & SD & $\mathbf{M}$ & SD & $P$ & $\mathbf{M}$ & SD & $\mathbf{M}$ & SD & $\mathbf{P}$ & $\mathbf{M}$ & SD & $\mathbf{M}$ & SD & $\mathbf{P}$ \\
\hline \multicolumn{16}{|l|}{ APQ } \\
\hline Mother involvement & 33.2 & 2.4 & 32.8 & 4.8 & ns & 37.6 & 2.9 & 33.1 & 4.3 & 0.001 & 38.0 & 3.8 & 33.3 & 3.2 & 0.005 \\
\hline Positive parenting & $25 \cdot 3$ & 3.8 & 24.1 & 3.6 & ns & 26.1 & 3.0 & 24.5 & 3.7 & ns & 27.0 & 3.1 & 25.1 & 3.5 & ns \\
\hline Inconsistent discipline & 18.8 & 5.2 & 19.2 & 5.39 & ns & 13.7 & 3.9 & 18.3 & 3.8 & 0.001 & 14.4 & 2.5 & 18.6 & 4.1 & 0.001 \\
\hline Poor parental monitoring & 19.3 & 2.7 & 18.5 & 5.1 & ns & 17.8 & 2.6 & 18.0 & 4.3 & ns & 17.6 & 2.7 & 17.1 & 4.3 & ns \\
\hline Corporal punishment & 8.2 & 2.3 & 8.0 & 2.3 & ns & 5.2 & 1.4 & 7.8 & 1.7 & 0.005 & 4.8 & 1.4 & 8.1 & 1.4 & 0.0005 \\
\hline PSS & 50.5 & 7.1 & 53.3 & 6.5 & ns & 45.7 & 7.1 & 52.8 & 5.0 & 0.001 & 46.1 & 6.8 & 52.2 & 4.0 & 0.05 \\
\hline
\end{tabular}

One mother in the treatment group could only attend 4 sessions and her post-test and follow-up data could not be collected at the end of the programme.

The differences between groups in pretest score were analysed using a test.

The group differences in post-test and follow-up were analysed using analysis of covariance (with pretest scores as the covariate).

$A P Q=$ Alabama Parenting Questionnaire; $M=$ mean; $n s=$ not significant; $P S S=$ Parental Stress Scale; $S D=$ standard deviation. 

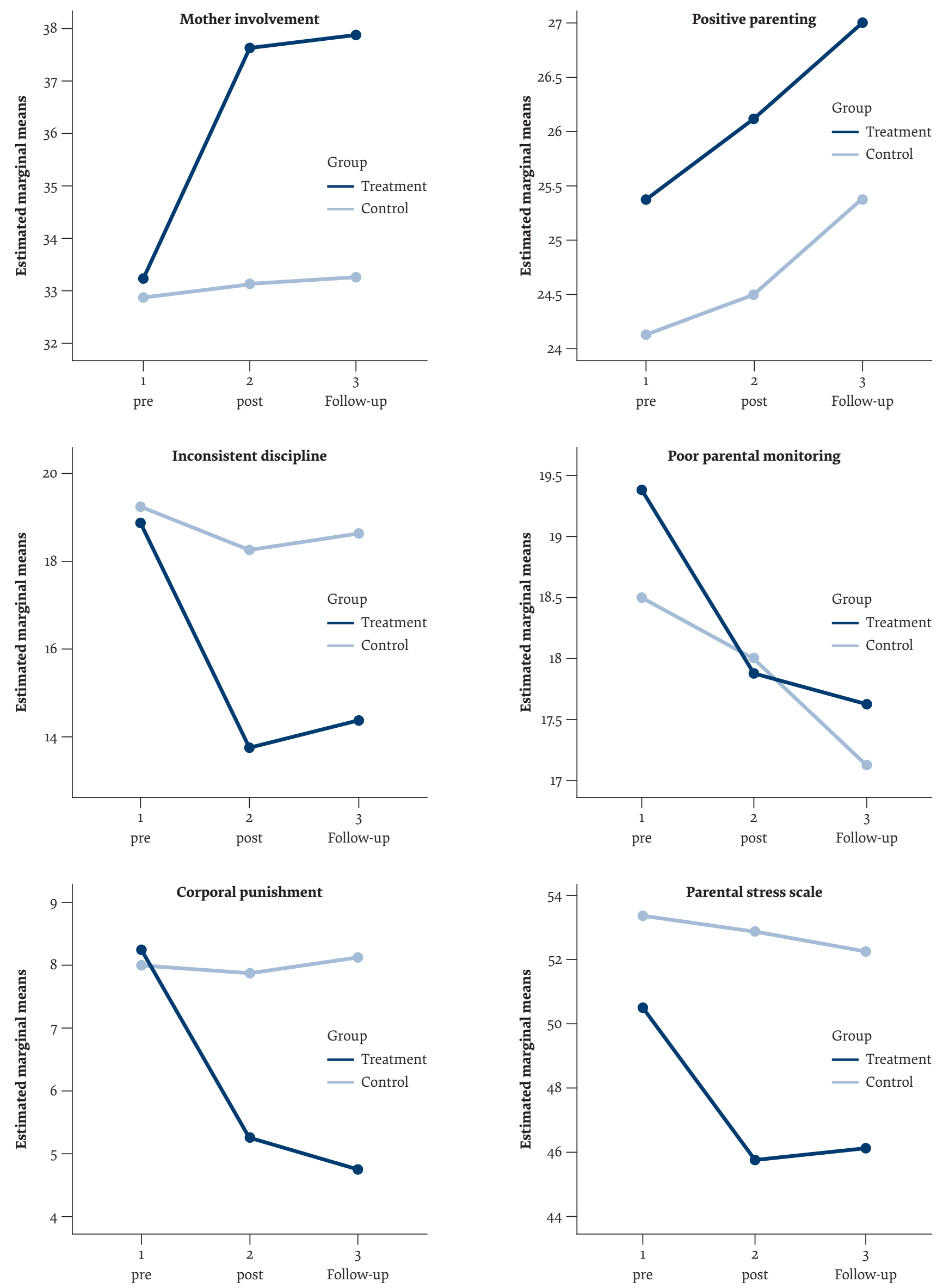

Figure 1 Changes in parenting styles and parental stress between groups 


\begin{tabular}{|c|c|c|c|c|c|c|c|c|c|}
\hline \multirow{3}{*}{ Variables } & \multicolumn{4}{|c|}{$\begin{array}{l}\text { Children whose mother attended } \\
\qquad(n=8)\end{array}$} & \multicolumn{4}{|c|}{$\begin{array}{l}\text { Children whose mother did not attend } \\
\qquad(n=8)\end{array}$} & \multirow[b]{3}{*}{$\mathbf{P}$} \\
\hline & \multicolumn{2}{|c|}{ Base line } & \multicolumn{2}{|c|}{ Post-test } & \multicolumn{2}{|c|}{ Base line } & \multicolumn{2}{|c|}{ Post-test } & \\
\hline & $\mathbf{M}$ & SD & $\mathbf{M}$ & SD & $\mathbf{M}$ & SD & $\mathbf{M}$ & SD & \\
\hline Academic self-concept & 74.5 & 12.3 & 78.5 & 11.4 & 76.5 & 8.6 & 77.0 & 10.3 & 0.13 \\
\hline \multicolumn{10}{|l|}{ SDQ } \\
\hline Prosocial behaviour & 5.4 & 1.06 & 7.0 & 0.84 & 6.4 & 2.4 & 6.7 & 1.67 & 0.12 \\
\hline Hyperactivity & 6.0 & 1.2 & 4.2 & 1.04 & 5.0 & 1.8 & 3.6 & 1.2 & 0.48 \\
\hline Emotional problems & 5.5 & 1.9 & 4.0 & 1.3 & 4.8 & 0.89 & 3.9 & 0.84 & 0.38 \\
\hline Conduct problems & 3.4 & 1.8 & 3.5 & 0.93 & 3.2 & 2.3 & 3.6 & 0.74 & 0.65 \\
\hline Peer problems & 3.4 & 1.1 & 3.6 & 0.92 & 4.4 & 1.4 & 4.6 & 0.73 & 0.13 \\
\hline Total difficulties & 18.2 & 2.0 & 15.3 & 2.9 & 17.0 & 1.9 & 15.8 & 1.8 & 0.30 \\
\hline Internalizing problems & 9.3 & 2.1 & 7.8 & 1.4 & 8.3 & 1.5 & 7.2 & 1.04 & 0.17 \\
\hline Externalizing problems & 8.9 & 2.2 & 7.6 & 2.0 & 9.13 & 1.3 & 8.5 & 1.1 & 0.59 \\
\hline
\end{tabular}

$M=$ mean; $S D=$ standard deviation; $S D Q=$ Strengths and Difficulties Questionnaire.

\begin{tabular}{|c|c|c|c|c|}
\hline \multicolumn{5}{|c|}{$\begin{array}{l}\text { Table } 4 \text { ANCOVA of academic self-con } \\
\text { problems among children }\end{array}$} \\
\hline \multicolumn{5}{|c|}{ Tests of between-subjects effects } \\
\hline Dependent variables & df & $\boldsymbol{F}$ & $\boldsymbol{P}$ & $\eta_{p}^{2}$ \\
\hline Academic self-concept & 1 & 2.57 & 0.13 & 0.16 \\
\hline \multicolumn{5}{|l|}{ SDQ } \\
\hline Prosocial behaviour & 1 & 2.71 & 0.12 & 0.17 \\
\hline Hyperactivity & 1 & 0.54 & 0.48 & 0.04 \\
\hline Emotional problems & 1 & 0.83 & 0.38 & 0.06 \\
\hline Conduct problems & 1 & 0.21 & 0.65 & 0.02 \\
\hline Peer problems & 1 & 2.56 & 0.13 & 0.16 \\
\hline Total difficulties & 1 & 1.2 & 0.30 & 0.08 \\
\hline Internalizing problems & 1 & 2.1 & 0.17 & 0.14 \\
\hline Externalizing problems & 1 & 0.30 & 0.59 & 0.02 \\
\hline
\end{tabular}

ANCOVA = analysis of covariance; $d f=$ degrees of freedom; $S D Q=$ Strengths and Difficulties Questionnaire.

interventions were found to be sustained over a period of time (3 months to 3 years).

However, there were no significant improvements in academic self-concept and behavioural problems for those children whose mothers attended the STEP programme compared with those that did not. These findings are similar to the results of Davis (31) who found no significant improvement in child behaviour after parents attended 4 sessions of STEP. The findings are also supported by a study by Clarkson (32) who found no significant differences in classroom performance and self-concept subscales (i.e., peer, school, family and general) between children whose parents attended a STEP programme and those whose parents did not. One reason for this finding may be that the children did not simultaneously attend STEP sessions with their mothers. Another reason may be related to the short duration of the intervention, during which time children did not show a direct benefit. It has also been argued that children who are vulnerable to harsh rearing practices are less affected by a positive rearing style (33); thus, the characteristics of these children need to be studied further to reach any firm conclusions.

Nevertheless, our results suggest that the STEP programme improved parenting style and reduced parental stress, which ultimately may be a key mechanism for change in their children's long-term psychological and behavioural outcomes. These findings are promising because it has previously been concluded that there is a strong relationship between parenting style and academic self-concept and behavioural problems (17). STEP offers strategies for parents with which they can engage with their children more effectively; therefore, using STEP strategies over a longer period of time may have an increasingly positive impact on reducing children's behavioural problems (34).

Our findings suggest that for Kurdish mothers the STEP programme is an effective intervention for the promotion of positive parenting style and a decline in parental stress. Our proof of concept study suggests that such a programme is accepted by Kurdish parents as a positive measure to improve their parenting skills, and that STEP can be used in low-income countries, particularly those with high prevalence rates of domestic violence and psychological and physical abuse. In addition, this intervention can be considered as a suitable training programme for parents. Mothers gave positive feedback after the intervention and confirmed that they would participate in the programme again in the future. They suggested that participation in STEP increased their motivation to read more information concerning parenting practice.

The current study had some strengths. The programme was tested in a developing country and it is believed to be the first study to evaluate the STEP intervention with mothers rather than fathers in a Muslim society where fathers normally take a leading role in the family. The study also indicates to concerned authorities in the Kurdistan Region that parenting interventions are effective for the Kurdish population. A further strength is that we recruited both treatment and control groups. 
This was not the case in most other studies of this topic. For example, from a systematic review by Smith (35), only 4 of 17 studies had a control group for comparison at follow-up, and the lack of a control group has been cited as a significant limitation of many studies.

Our study also had some limitations. First, although a STEP class size of 6-14 parents is considered optimal, the STEP programme needs to be repeated with several groups to increase the sample size and statistical power. Given the small sample size in our study, the findings should be interpreted with caution, and it was not possible to control all confounding variables. Second, the participants were all Kurdish; hence, the results may not be generalized to other ethnic groups. The sample was mothers rather than fathers, which again affects generalization. Third, this study focused only on parental self-reports and did not include any parental interviews or observational data on maternal behaviour. Fourth, followup was short term (3 months). Fifth, child behaviour profile on the SDQ was reported by teachers. However, it might have been useful to detect negative behaviours in > 1 setting; therefore, multi-informant reporting by teachers and parents may help to overcome some of the bias involved in single-informant studies. Future research needs to obtain data from a larger sample, collect data from multiple informants, recruit both parents, and could potentially include specific groups, for example, parents with children with learning disabilities.

\section{Implications for practice}

The results of this study are consistent with most studies in the literature that emphasize the effectiveness of STEP programmes in improving a range of parental behaviours. Our results indicate that STEP can be implemented in low-income and developing countries, particularly those that have high rates of domestic violence and psychological and physical abuse. The findings of the study also indicate that experts such as primary care professionals, educators and psychologists could have an important role to play in supporting parents to improve parenting style and decrease levels of parental stress.

Funding: Ministry of Higher Education - KRG; Department of Psychology, University of Durham, United Kingdom.

Competing interests: None declared.

\section{Effets des interventions parentales sur les comportements et l'état psychologique pour les parents et les enfants kurdes}

\section{Résumé}

Contexte : Les interventions parentales sont rarement proposées dans les pays en développement et il existe un besoin urgent qu'elles le soient également dans les pays à revenu faible.

Objectifs: Examiner l'efficacité du programme éducatif appelé Approche systématique pour une parentalité efficace (STEP) parmi les parents et les enfants kurdes.

Méthodes : Il s'agissait d'un essai pilote contrôlé randomisé utilisant les résultats avant et après la formation menée auprès de 17 mères (âge moyen de 35,25 ans, ET 4,3 ans, compris entre 29,58 et 45,3 ans) qui avaient accepté de participer à cette intervention. Nous avons utilisé le Questionnaire parental d'Alabama afin d'évaluer le style parental, l'Échelle de stress parental afin d'examiner le stress lié à la parentalité, et la Technique d'évaluation de la parentalité selon l'approche STEP afin de déterminer si les participants du groupe témoin avaient pris connaissance de la documentation de l'intervention.

Résultats : Nous avons observé des différences significatives entre les groupes sur trois sous-échelles du Questionnaire parental d'Alabama : la sous-échelle de l'engagement maternel $\left(F(1,13)=25,81, p<0,001, \eta_{p}^{2}=0,67\right)$; la sous-échelle de la discipline inconsistante $\left(F(1,13)=25,46, p<0,001, \eta^{2}=0,66\right)$; et la sous-échelle des punitions corporelles $(F(1,13)=$ $\left.17,3, p<0,005, \eta_{p}^{2}=0,57\right)$. Il y avait également une différence significative entre les groupes selon l'Échelle de stress parental $\left(F(1,13)=19,63, p<0,001, \eta_{p}^{2}=0,60\right)$. Ces différences se maintenaient sur une période de trois mois. Aucune différence notable n'a été trouvée dans l'auto-perception scolaire et les problèmes comportementaux des enfants dont les mères avaient participé à l'approche STEP et ceux dont les mères n'y avaient pas participé.

Conclusion : Il semblerait que l'approche STEP permette d'améliorer le style de parentalité et réduise le niveau de stress parental chez les mères kurdes. 


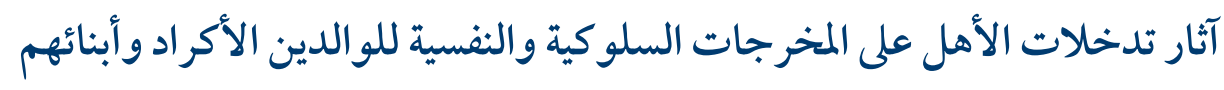

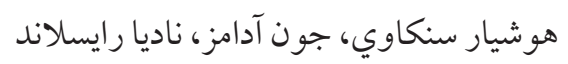

الخلفية: لقد وجد أن الثدخلات الخاصة بتنشئة الأطفال نادراً ما تُقدم في البلدان النامية، وثمة حاجة ملحة لإشراك البلدان المنخفضة الدخل.

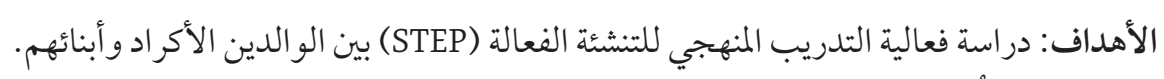

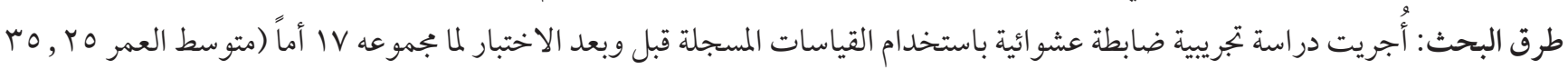

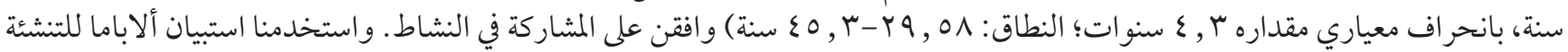

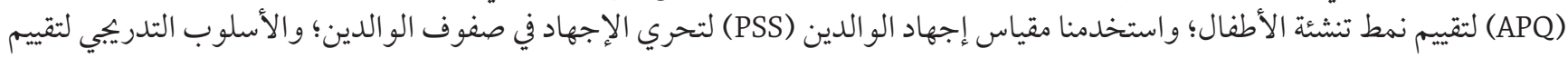

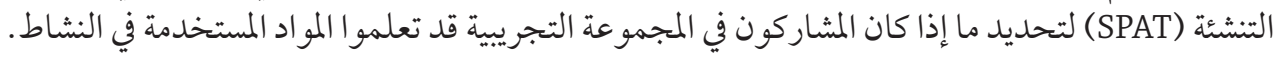

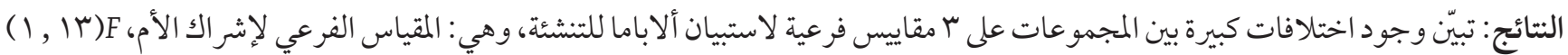

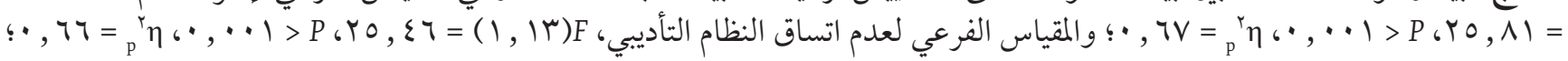

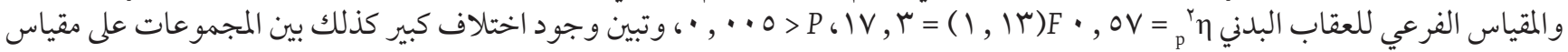

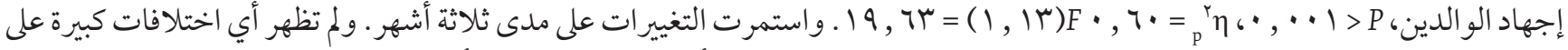

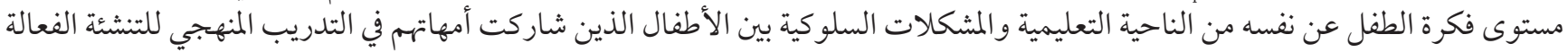
(STEP)

الاستنتاج: يبدو أن برنامج التدريب المنهجي للتنشئة الفعالة يعمل على تحسين أسلوب تنشئة الأطفال وخفض مستوى الإجهاد المرتبط بالتنشئة لدى الأمهات الكرديات.

\section{References}

1. Chan TW, Koo A. Parenting style and youth outcomes in the UK. Eur Sociol Rev. 2011 Jun;27(3):385-99. https://doi.org/10.1093/esr/ jcqo13

2. Sangawi HS, Adams J, Reissland N. The effects of parenting styles on behavioral problems in primary school children: a crosscultural review. Asian Soc Sci. 2015;11(22):171-86. http://dx.doi.org/10.5539/ass.v11n22p171

3. Preventing violence through the development of safe, stable and nurturing relationships between children and their parents and caregivers. Geneva: World Health Organization; 2009 (http://www.who.int/iris/handle/10665/44088, accessed 20 January 2018).

4. Bunting L. Parenting programmes: the best available evidence. Child Care Pract. 2004;10(4):327-43. https://doi. org/10.1080/1357527042000285510

5. Barlow J, Coren E, Stewart-Brown S. Meta-analysis of the effectiveness of parenting programmes in improving maternal psychosocial health. Br J Gen Pract. 2002 Mar;52(476):223-33. PMID:12030667

6. Dinkmeyer D. McKay GD. The parent's handbook: systematic training for effective parenting. Fredericksburg, VA: STEP Publishers; 1997.

7. Collins CL, Fetsch RJ. A review and critique of 16 major parent education programs. J Extension. 2012 Aug;50(4):4FEA8. https://joe. org/joe/2012august/a8.php

8. Jonyniene J, Kern R, Gfroerer K. Efficacy of Lithuanian Systematic Training for Effective Parenting (STEP) on parenting style and perception of child behavior. Fam J. 2015;23(4):392-406. https://doi.org/10.1177/1066480715574473

9. Larson BJ. Systematic training for effective parenting of teens (STEP/Teen): parental authority, adolescent externalizing behavior, and parent-child relationships [thesis]. Almeda (CA): California School of Professional Psychology; 2000.

10. Pan $\mathrm{Z}$, Wu X. A study on the effect of systematic training for effective parenting on improving the parent-child relation. Chin J Clin Psychol. 2008;16(4):446-7 (in Chinese).

11. Huebner CE. Evaluation of a clinic-based parent education program to reduce the risk of infant and toddler maltreatment. Public Health Nurs. 2002 Sep-Oct;19(5):377-89. https://doi.org/10.1046/j.1525-1446.2002.19507.x PMID:12182697

12. Wantz RA, Recor R D. Simultaneous parent-child group intervention. Elem Sch Guid Couns. 1984;19(2):126-31.

13. Thomas H, Camiletti Y, Cava M, Feldman R, Underwood J, Wade K. Effectiveness of parenting groups with professional involvement in improving parent and child outcomes. Effective Public Health Practice Project;1999. (http://bit.ly/1OqNNLl, accessed 20 January 2018).

14. Knerr W, Gardner F, Cluver L. Improving positive parenting skills and reducing harsh and abusive parenting in low- and middleincome countries: a systematic review. Prev Sci. 2013 Aug;14(4):352-63. https://doi.org/10.1007/s11121-012-0314-1 PMID:23315023

15. Mejia A, Calam R, Sanders MR. A review of parenting programs in developing countries: opportunities and challenges for preventing emotional and behavioral difficulties in children. Clin Child Fam Psychol Rev. 2012 Jun;15(2):163-75. https://doi. 
org/10.1007/s10567-012-0116-9 PMID:22427004

16. Saed BA, Talat LA, Saed BA. Prevalence of childhood maltreatment among college students in Erbil, Iraq. East Mediterr Health J. 2013 May;19(5):441-6. PMID:24617122

17. Sangawi H, Adams J, Reissland N. The impact of parenting styles on children developmental outcome: The role of academic selfconcept as a mediator. Int J Psychol. 2016 Aug 23; https://doi.org/10.1002/ijop.12380 PMID:27554170

18. Goodman R. The Strengths and Difficulties Questionnaire: a research note. J Child Psychol Psychiatry. 1997 Jul;38(5):581-6. https://doi.org/10.1111/j.1469-7610.1997.tbo1545.x PMID:9255702

19. Australian Mental Health Outcomes and Classification Network. Strengths and Difficulties Questionnaire training manual. NSW Institute of Psychiatry; 2005 (http://www.amhocn.org/sites/default/files/publication_files/sdq_manual_o.pdf, accessed 20 January 2018).

20. Lamb ME, Lewis $\mathrm{C}$. The development and significance of father-child relationships in two-parent families. In: Lamb ME, editor. The role of the father in child development. Hoboken (NJ): Wiley; 2004:272-307.

21. Grolnick WS, Ryan RM. Parent styles associated with children's self-regulation and competence in school. J Educ Psychol. 1989;81(2):143-54. https://doi.org/10.1037/0022-0663.81.2.143

22. Burden R. Assessing children's perceptions of themselves as learners and problem-solvers: the construction of the Myself-asLearner Scale (MALS). School Psychol Int. 1998;19(4):291-305. https://doi.org/10.1177/0143034398194002

23. Shelton KK, Frick PJ, Wootton J. Assessment of parenting practices in families of elementary school-age children. J Clin Child Psychol. 1996;25(3):317-29. https://doi.org/10.1207/s15374424jccp2503_8

24. Berry JO, Jones WH. The Parental Stress Scale: initial psychometric evidence. J Soc Pers Relat. 1995;12(3):463-72. https://doi. org/10.1177/0265407595123009

25. Huitema B. Analysis of covariance (ANCOVA). In: Salkind NJ, Rasmussen K, editors. Encyclopedia of measurement and statistics. Thousand Oaks (CA): Sage; 2007:30-3.

26. Kline RB. Principles and practice of structural equation modeling. 3rd edition. New York: Guilford Press; 2011.

27. Statistics \& Methods Centre - (M)AN(C)OVA models (http://bit.ly/1Kd3dkH, accessed 20 January 2018).

28. Sharpley CF, Poiner AM. An exploratory evaluation of the Systematic Training for Effective Parenting (STEP) programme. Aust Psychol. 1980;15(1):103-9.

29. Hautmann C, Hoijtink H, Eichelberger I, Hanisch C, Plück J, Walter D, et al. One-year follow-up of a parent management training for children with externalizing behaviour problems in the real world. Behav Cogn Psychother. 2009 Jul;37(4):379-96. https://doi. org/10.1017/S135246580999021X PMID:19619384

30. Webster-Stratton C, Hollinsworth T, Kolpacoff M. The long-term effectiveness and clinical significance of three cost-effective training programs for families with conduct-problem children. J Consult Clin Psychol. 1989 Aug;57(4):550-3. https://doi. org/10.1037/0022-006X.57.4.550 PMID:2504794

31. Davis LAJ. The effect of parent involvement training on the achievement of Hispanic students [thesis]. University of North Texas; 1994.

32. Clarkson PJ. Effects of parent training and group counseling on children's functioning in elementary school. Diss Abstr Int. 1979;39(8-A):4726-7.

33. Jarrett C. Some children are extra sensitive to parenting styles, bad and good. British Psychological Society Research Digest. 12 October 2016 (http://bit.ly/2lAGgCC, accessed 20 January 2018).

34. Spence JA. Changes in perception of family environment and self-reported symptom status in adolescents whose parents participate in an Adlerian parent-training intervention. Proquest, UMI Dissertation Publishing; 2011.

35. Smith R. An evaluation of parenting groups for children with behavioural difficulties [thesis]. University of Birmingham; 2013. 